\title{
Tetracosahexaenoic Acid
}

National Cancer Institute

\section{Source}

National Cancer Institute. Tetracosahexaenoic Acid. NCI Thesaurus. Code C68428.

A polyunsaturated fatty acid with a 24-carbon backbone and six double bonds. Three stereoisomers of Tetracosahexaenoic acid are recognized. 